Virginia Commonwealth University vCU Scholars Compass

\title{
Quality of Life in Chronic Pancreatitis is
} Determined by Constant Pain, Disability/ Unemployment, Current Smoking, and Associated Co-Morbidities

Jorge D. Machicado

University of Pittsburgh

Stephen T. Amann

North Mississippi Medical Center

Michelle A. Anderson

University of Michigan

See next page for additional authors

Follow this and additional works at: http://scholarscompass.vcu.edu/path_pubs

Part of the Pathology Commons

(C) 2017 by the American College of Gastroenterology

\section{Downloaded from}

http://scholarscompass.vcu.edu/path_pubs/12

This Article is brought to you for free and open access by the Dept. of Pathology at VCU Scholars Compass. It has been accepted for inclusion in Pathology Publications by an authorized administrator of VCU Scholars Compass. For more information, please contact libcompass@vcu.edu. 


\section{Authors}

Jorge D. Machicado, Stephen T. Amann, Michelle A. Anderson, Judah Abberbock, Stuart Sherman, Darwin L. Conwell, Gregory A. Cote, Vikesh K. Singh, Michele D. Lewis, Samer Alkaade, Bimaljit S. Sandhu, Nalini M. Guda, Thiruvengadam Muniraj, Gong Tang, John Baillie, Randall E. Brand, Timothy B. Gardner, Andres Gelrud, Christopher E. Forsmark, Peter A. Banks, Adam Slivka, C. Mel Wilcox, David C. Whitcomb, and Dhiraj Yadav 


\title{
Quality of Life in Chronic Pancreatitis is Determined by Constant Pain, Disability/Unemployment, Current Smoking, and Associated Co-Morbidities
}

\author{
Jorge D. Machicado, MD¹, Stephen T. Amann, MD², Michelle A. Anderson, MD, MSc ${ }^{3}$, Judah Abberbock, $\mathrm{MS}^{1}$, Stuart Sherman, MD4,

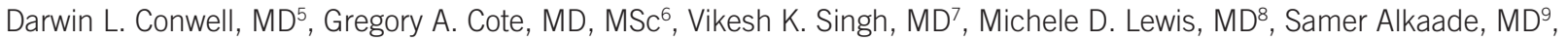 \\ Bimaljit S. Sandhu, MDD ${ }^{10}$, Nalini M. Guda, MD ${ }^{11}$, Thiruvengadam Muniraj, MD ${ }^{12}$, Gong Tang, PhD ${ }^{1}$, John Baillie, MBChB ${ }^{13}$, \\ Randall E. Brand, MD ${ }^{1}$, Timothy B. Gardner, MD ${ }^{14}$, Andres Gelrud, MD, MMSc ${ }^{15}$, Christopher E. Forsmark, MD ${ }^{16}$, Peter A. Banks, MD ${ }^{17}$, \\ Adam Slivka, MD, PhD ${ }^{1}$ C. Mel Wilcox, MD, MSPH ${ }^{18}$, David C. Whitcomb, MD, $\mathrm{PhD}^{1}$ and Dhiraj Yadav, MD, MPH ${ }^{1}$
}

OBJECTIVES: Chronic pancreatitis (CP) has a profound independent effect on quality of life (QOL). Our aim was to identify factors that impact the QOL in CP patients.

METHODS: $\quad$ We used data on 1,024 CP patients enrolled in the three NAPS2 studies. Information on demographics, risk factors, co-morbidities, disease phenotype, and treatments was obtained from responses to structured questionnaires. Physical and mental component summary (PCS and MCS, respectively) scores generated using responses to the Short Form-12 (SF-12) survey were used to assess QOL at enrollment. Multivariable linear regression models determined independent predictors of QOL.

RESULTS: $\quad$ Mean PCS and MCS scores were $36.7 \pm 11.7$ and $42.4 \pm 12.2$, respectively. Significant $(P<0.05)$ negative impact on PCS scores in multivariable analyses was noted owing to constant mild-moderate pain with episodes of severe pain or constant severe pain (10 points), constant mild-moderate pain (5.2), pain-related disability/unemployment (5.1), current smoking (2.9 points), and medical co-morbidities. Significant $(P<0.05)$ negative impact on MCS scores was related to constant pain irrespective of severity (6.8-6.9 points), current smoking (3.9 points), and pain-related disability/ unemployment (2.4 points). In women, disability/unemployment resulted in an additional 3.7 point reduction in MCS score. Final multivariable models explained $27 \%$ and $18 \%$ of the variance in PCS and MCS scores, respectively. Etiology, disease duration, pancreatic morphology, diabetes, exocrine insufficiency, and prior endotherapy/pancreatic surgery had no significant independent effect on QOL.

CONCLUSIONS: Constant pain, pain-related disability/unemployment, current smoking, and concurrent co-morbidities significantly affect the QOL in CP. Further research is needed to identify factors impacting QOL not explained by our analyses.

Am J Gastroenterol 2017; 112:633-642; doi:10.1038/ajg.2017.42; published online 28 February 2017

\section{INTRODUCTION}

Chronic pancreatitis (CP), a chronic inflammatory disorder of the pancreas, is characterized by irreversible morpho- logical changes of the pancreas, abdominal pain-which is often chronic and debilitating, episode(s) of acute pancreatitis (AP), impairment of endocrine and exocrine function, and

\footnotetext{
${ }^{1}$ University of Pittsburgh Medical Center, Pittsburgh, Pennsylvania, USA; ${ }^{2}$ North Mississippi Medical Center, Tupelo, Mississippi, USA; ${ }^{3}$ University of Michigan, Ann Arbor, Michigan, USA; ${ }^{4}$ Indiana University, Indianapolis, Indiana, USA; 5 Ohio State University, Columbus, Ohio, USA; ${ }^{\circ}$ Medical University of South Carolina, Charleston, South Carolina, USA; ${ }^{7}$ Johns Hopkins Medical Institutions, Baltimore, Maryland, USA; ${ }^{8}$ Mayo Clinic, Jacksonville, Florida, USA; ${ }^{9}$ Saint Louis University, St Louis, Missouri, USA; ${ }^{10}$ Richmond Gastroenterology Associates, Richmond, Virginia, USA; ${ }^{11}$ Aurora Health Care, Milwaukee, Wisconsin, USA; ${ }^{12}$ Yale School of Medicine, New Haven, Cincinnati, USA; ${ }^{13}$ Virginia Commonwealth University, Richmond, Virginia, USA; ${ }^{14}$ Dartmouth Hitchcock Medical Center, Lebanon, New Hampshire, USA; ${ }^{15}$ University of Chicago, Chicago, Illinois, USA; ${ }^{16}$ University of Florida, Gainesville, Florida, USA; ${ }^{17}$ Brigham and Women's Hospital, Boston, Massachusetts, USA; ${ }^{18}$ University of Alabama at Birmingham, Birmingham, Alabama, USA. Correspondence: Dhiraj Yadav, MD, MPH, Division of Gastroenterology \& Hepatology and Nutrition, Department of Medicine, University of Pittsburgh Medical Center, 200 Lothrop Street, M2, C-wing, Pittsburgh, Pennsylvania 15213, USA. E-mail: yadavd@upmc.edu

Received 27 October 2016; accepted 9 January 2017
} 
in a small subset of patients, development of pancreatic cancer (1).

In previous single-center studies, quality of life (QOL) in patients with CP was noted to be significantly impaired when compared with historical population controls $(2,3)$. In a large, multicenter study, we demonstrated a profound effect of $\mathrm{CP}$ on physical and a modest effect on mental QOL when compared with subjects without pancreatitis, independent of demographics, risk factors, etiology, and common medical conditions (4). Although these data document the poor QOL in CP patients, they do not provide an explanation for the factors responsible for this observation. Understanding these factors is of importance in the clinical management of patients, especially if they can be modified by behavioral changes, treatment of disease, or its complications.

Studies evaluating independent factors associated with low QOL in CP patients have consistently reported abdominal pain to be an important predictor (3,5-10). Treatment of pain by surgical or endoscopic therapy has documented effect not only in achieving pain relief but also in improving QOL (11-14). Etiology of CP has not been found to affect QOL $(3,5,8)$. Younger age, female sex, smoking, alcohol consumption, low body mass index, diabetes, exocrine pancreatic insufficiency, pancreatic morphology, and disease duration lower QOL, but their association has been inconsistent across studies $(3,5,7,8,10)$. The reasons for this inconsistency include variability in the instruments used to determine QOL, small sample size of studies, and the lack of use of uniform predictor variables. The effect of pain-related disability or unemployment on QOL has not been adequately studied.

The North American Pancreatitis Study 2 (NAPS2) studies have prospectively ascertained over 1,000 well-phenotyped patients with CP from several US centers. Systematically collected data on QOL and several potential predictor variables provided us with an opportunity to determine which factors may affect QOL in this cohort.

\section{METHODS}

\section{Study population}

We utilized data from the NAPS2 studies for this analysis. NAPS2 consists of a series of three studies (original NAPS2, NAPS2-CV, and NAPS2-AS) from 27 centers in the United States that prospectively ascertained 1,195 CP, 569 recurrent AP and 1,109 controls from 2000 to 2014. One of the participating centers only enrolled control subjects. Detailed methodology for the NAPS2 studies has been published (15-17). CP was defined by definitive changes on imaging studies (primarily endoscopic retrograde cholangiopancreatography or computed tomography scan or equivalent changes on magnetic resonance cholangiopancreatography or endoscopic ultrasound) or histology. The study was approved by the Institutional Review Board of each center and all subjects provided written informed consent prior to enrollment.

The present study includes 1,024/1,195 (85.6\%) CP patients from the three NAPS2 studies who provided complete responses for determination of QOL, disability/unemployment, and pain characteristics (pain pattern and severity).

\section{Data collection}

Study subjects completed a detailed questionnaire, including information on demographics, family and personal history, exposure to smoking and alcohol, pain experience, disability/ unemployment related to pain from pancreatitis, and QOL. Selfreported alcohol use during the maximum drinking period of life was used to create drinking categories (abstainers: no alcohol use or $<20$ drinks in a lifetime; light drinkers: $\leq 3$ drinks per week; moderate drinkers: 4-7 drinks per week for females and 4-14 drinks per week for males; heavy drinkers: 8-34 drinks per week for females and 15-34 drinks per week for males; very heavy drinkers: $\geq 35$ drinks per week for both sexes) and smoking (status: never, past, current; amount: $<1$ packs per day or $\geq 1$ packs per day; and $<12,12-35$, and $\geq 35$ pack-years) as described previously (15).

The enrolling physician investigator completed a separate questionnaire consisting of information on etiology, TIGAR-O ((i) Toxic-metabolic (ii) Idiopathic (iii) Genetic (iv) Autoimmune (v) Recurrent and severe AP or (vi) obstructive) risk factors, phenotypic characteristics (history of AP, age at AP, age at the onset of $\mathrm{CP}$ symptoms, age at CP diagnosis, presence of diabetes, exocrine insufficiency, imaging features), and treatments received (medications, surgical and endoscopic interventions), and their perceived effectiveness.

\section{QOL evaluation}

The Short Form-12 (SF-12) version 2 was used to assess QOL in the NAPS2-CV and NAPS2-AS studies. In the original NAPS2 study, QOL was assessed using the SF-12 version 1, and scores were transformed to version 2 for interpretation (18). SF-12 is a multipurpose generic QOL questionnaire that was derived from the SF-36 Health Survey $(18,19)$. The SF-36 and SF-12 have been validated in several languages and disease conditions, including $\mathrm{CP}(2,3,20)$. The SF-12 is comprised of 12 questions that measure 8 domains (role physical, role emotional, physical function, social function, mental health, vitality, bodily pain, and general health) and can be summarized into the physical component summary (PCS) and mental component summary (MCS) scores. SF-12 questionnaire takes approximately $2 \mathrm{~min}$ to complete without a significant loss of information and is based on a standard recall of 4 weeks (18). The summary scores for each domain are then transformed to $z$-scores using the SF-12 scale means and s.d. from the 1998 general US population to produce a normally distributed population score. PCS and MCS scores range from 0 to 100 with a score of $50 \pm 10$ representing the mean \pm s.d. for the general population. These scores provide a direct comparison of the distribution in the population of interest when compared with the general population and between groups. A difference of three points in the PSC or MCS scores between groups has been suggested to be clinically relevant (4).

\section{Pain and disability/unemployment assessment}

We used patient-reported pain experience for all comparisons in this study. In the NAPS2-CV and NAPS2-AS studies, there was a leading question on the presence of pain (i.e., Have you 
experienced abdominal pain related to pancreatitis in the past year?). Patients who reported "yes" were asked to choose from one of the five predefined pain patterns (episodes of mild-tomoderate pain; constant mild-to-moderate pain; usually pain free with episodes of severe pain; constant mild pain plus episodes of severe pain; and constant severe pain that does not change). For this study, we incorporated the presence, severity, and temporal nature of pain to classify patients into the following five categories: (i) No pain; (ii) Intermittent mild-to-moderate episodes of pain; (iii) Intermittent severe episodes of pain; (iv) Constant mild-to-moderate pain; and (v) Constant mild-to-moderate pain with episodes of severe pain or constant severe pain that does not change. In the original NAPS2 study, a leading question on the presence of pain was not asked and patients were directly asked to complete the question in the five pain patterns (15). Therefore, patients in the original NAPS2 study who did not identify with a pain pattern were excluded from the final analysis $(n=126)$ as it is impossible to distinguish those patients without pain and those with pain who simply left their pain category blank. In addition, patients from the three NAPS2 studies were asked for the presence of pain-related disability or unemployment.

\section{Statistics}

The PCS and MCS scores were computed using the scoring method system provided in the SF-12 version 2 reference manual and presented as mean \pm s.d. (18). Descriptive analyses are presented as proportions for categorical data and as mean \pm s.d. for continuous data. Comparison between the PCS and MCS scores within each group variable was carried out using Kruskal-Wallis test. All variables with a $P$-value of $<0.2$ on univariate analysis comparing the PCS and MCS scores were considered for potential inclusion in the multivariable models.

Multivariable linear regression models were used to determine the independent predictors of physical and mental QOL. A backwards selection technique was used to determine significant independent predictors. Age and gender were included in both final models because of clinical significance. Other variables were removed one by one in order of the magnitude of the $P$-value for the type III F-test, with the exception of diabetes which was removed from the PCS model owing to its small effect size compared with the other variables remaining. Models were then re-run until a final model was reached containing only the variables with $P<0.05$. For the MCS final model, history of liver disease was borderline significant and was included in the final model. There were missing data in some variables, but in no case did they exceed $\sim 6 \%$. The PCS model was not examined for interactions to maintain easier interpretation and out of concern of including too many variables in the final model. Significant interactions were examined for the MCS model. For easier interpretation, the final models were centered at the age of 50 years. As the original NAPS2 study used an earlier version of SF12 and the presence of pain was not assessed by a leading question, a sensitivity analysis was performed after excluding these patients and using the same variables included in the final models. Data analysis was performed using SAS version 9.4 (SAS Institute Inc., Cary, NC).

\section{RESULTS}

\section{Demographics, risk factors, and clinical characteristics}

Of the 1,024 CP patients who formed the final study cohort, 381 (37.2\%) were enrolled in the original-NAPS2 study, 510 (49.8\%) in the NAPS2-CV study, and $133(13.0 \%)$ in the NAPS2-AS study. The distribution of baseline socio-demographic and clinical characteristics is shown in Table $\mathbf{1}$.

Overall, patients had a mean age of $50.4 \pm 14.6$ years, $54.6 \%$ were male, $74.8 \%$ were white, $19.6 \%$ were current drinkers, and the majority had a normal/low body mass index (57.6\%). Heavy or very heavy drinking during the maximum drinking period of life was reported by $15.1 \%$ and $34.9 \%$ and past or current smoking by $25.3 \%$ and $50.1 \%$ patients, respectively. Physicians considered alcohol as the main etiological factor in about half of (50.2\%) patients. In $>50 \%$ patients $(54.6 \%$ ), the duration of $\mathrm{CP}$ was $\geq 4$ years.

In our final study cohort, abdominal pain in the year preceding enrollment was present in $91.6 \%$. The most common pattern of abdominal pain identified was constant mild-to-moderate pain with episodes of severe pain or constant severe pain (48.5\%). Less frequently patients identified intermittent episodes of severe pain (24\%), intermittent episodes of mild-to-moderate pain $(12.8 \%)$, and constant mild-to-moderate pain (6.3\%). Pain-related disability/unemployment was reported by $27.1 \%$ of patients. About one-third of patients had exocrine insufficiency $(38.1 \%)$ or diabetes $(33.1 \%)$. Although $40.3 \%$ received only medical management, a prior history of pancreatic endotherapy was noted in $37.7 \%$ and pancreatic surgery in $21.5 \%$ patients. Almost half of the patients (44.3\%) had history of gallstones or cholecystectomy. The most commonly reported co-morbidities noted were heart disease/heart attack/stroke (11.8\%), liver disease $(9 \%)$, renal disease $(6.1 \%)$, or prior history of cancer (3.7\%).

\section{Predictors of physical QOL}

Univariable analysis. Mean PCS score for the study cohort was $36.7 \pm 11.7$. Univariable analysis for PCS scores based on demographics, risk factors, and clinical characteristics are shown in Table 1. A significantly lower physical QOL was noted with younger age, female sex, black race, extremes of alcohol consumption, current smoking, disability/unemployment, pain, and diabetes. A medical history of heart disease/heart attack/stroke, cancer, liver disease, renal disease, gallstones, or cholecystectomy was also significantly associated with lower PCS scores. Interestingly, the association was only borderline with disease duration, and no association was noted with body mass index, etiology, exocrine insufficiency, pancreatic morphology, prior endotherapy, or pancreatic surgery.

Multivariable analysis. Results for multivariable regression analyses for physical QOL are shown in Table 2. Temporal nature and severity of pain had the greatest impact on physical QOL. Compared with patients with no pain, constant mild-to-moderate pain with episodes of severe pain or constant severe pain reduced the PCS score by 10 points, while constant mild-to-moderate pain alone decreased it by 5.2 points. Presence of severe pain that was intermittent was also important but the impact of this (2.6 points) 
Table 1. Predictors of physical and mental QOL for CP patients in the NAPS2 study

\begin{tabular}{|c|c|c|c|c|c|}
\hline \multirow[t]{2}{*}{ Variable $(n=1,024)$} & \multirow[t]{2}{*}{$N(\%)$} & \multicolumn{2}{|c|}{ Physical QOL score } & \multicolumn{2}{|c|}{ Mental QOL score } \\
\hline & & Mean \pm s.d. & $P$-value & Mean \pm s.d. & $P$-value \\
\hline \multicolumn{6}{|l|}{ Study type } \\
\hline NAPS2-CV & $510(49.8)$ & $36.9 \pm 12.1$ & & $42.2 \pm 12.7$ & \\
\hline NAPS2-AS & $133(13.0)$ & $34.5 \pm 10.9$ & & $40.6 \pm 11.9$ & \\
\hline$<45$ & $344(33.5)$ & $36.5 \pm 11.3$ & $<0.001$ & $41.1 \pm 12.2$ & $<0.001$ \\
\hline $45-60$ & $427(41.7)$ & $35.6 \pm 11.5$ & & $40.7 \pm 11.9$ & \\
\hline$>60$ & $253(24.8)$ & $39.1 \pm 12.2$ & & $47.2 \pm 11.7$ & \\
\hline \multicolumn{6}{|l|}{ Gender } \\
\hline Male & $559(54.6)$ & $37.5 \pm 12.0$ & 0.02 & $42.9 \pm 12.1$ & 0.15 \\
\hline Caucasian & $765(74.8)$ & $36.2 \pm 10.8$ & & $43.0 \pm 12.3$ & \\
\hline Other & $30(2.9)$ & $37.2 \pm 11.8$ & & $40.6 \pm 12.4$ & \\
\hline \multicolumn{6}{|c|}{ Body mass index $(n=1,017)$} \\
\hline Normal/low & $586(57.6)$ & $36.5 \pm 11.7$ & 0.5 & $42.5 \pm 12.4$ & 0.8 \\
\hline Overweight & $275(27)$ & $37.4 \pm 11.9$ & & $42.1 \pm 12.2$ & \\
\hline Obese & $156(15.4)$ & $36.1 \pm 11.1$ & & $42.6 \pm 11.8$ & \\
\hline \multicolumn{6}{|l|}{ Smoking $(n=1,022)$} \\
\hline Never & $251(24.6)$ & $39.2 \pm 12.0$ & $<0.001$ & $45.1 \pm 10.7$ & $<0.001$ \\
\hline Abstainer & $171(17.1)$ & $35.5 \pm 11.0$ & $<0.001$ & $43.2 \pm 12.1$ & $<0.001$ \\
\hline Light & $170(17.0)$ & $37.4 \pm 11.6$ & & $44.9 \pm 11.7$ & \\
\hline Moderate & 159 (15.9) & $40.2 \pm 12.2$ & & $44.2 \pm 11.2$ & \\
\hline Heavy & $151(15.1)$ & $37.2 \pm 12.0$ & & $42.2 \pm 12.0$ & \\
\hline Very heavy & 347 (34.9) & $35.3 \pm 11.4$ & & $40.0 \pm 12.6$ & \\
\hline \multicolumn{6}{|l|}{ Alcohol etiology } \\
\hline Yes & $510(49.8)$ & $36.0 \pm 11.2$ & 0.06 & $40.9 \pm 12.3$ & $<0.001$ \\
\hline No & $513(50.2)$ & $37.4 \pm 12.1$ & & $44.0 \pm 12.0$ & \\
\hline \multicolumn{6}{|c|}{ Disease duration, years $(n=968)$} \\
\hline$\leq 1$ & $103(10.7)$ & $37.4 \pm 12.6$ & 0.06 & $45.1 \pm 11.6$ & 0.008 \\
\hline $1-<2$ & $122(12.6)$ & $38.2 \pm 12.5$ & & $43.9 \pm 12.9$ & \\
\hline $2-<3$ & $117(12.1)$ & $35.8 \pm 11.3$ & & $40.9 \pm 12.4$ & \\
\hline $3-<4$ & $97(10.0)$ & $39.5 \pm 11.1$ & & $40.3 \pm 12.8$ & \\
\hline$\geq 4$ & $529(54.6)$ & $36.2 \pm 11.4$ & & $42.2 \pm 11.9$ & \\
\hline \multicolumn{6}{|l|}{ Pain pattern } \\
\hline No pain & $86(8.4)$ & $43.7 \pm 11.9$ & $<0.001$ & $48.7 \pm 11.8$ & $<0.001$ \\
\hline
\end{tabular}




\section{Table 1. Continued}

\section{Variable $(n=1,024)$}

Intermittent mild-to-moderate episodes of pain

Intermittent severe episodes of pain

Constant mild-to-moderate pain

Constant mild-to-moderate pain with episodes of severe pain or constant severe pain

Disability/unemployment

Yes

No

Exocrine insufficiency

Yes

No

Endocrine insufficiency

Yes

No

Pseudocysts

Yes

No

Pancreatic surgery

Yes

No

Endoscopic therapy

Pancreatic endotherapy

Other endotherapy

None

History of heart disease/heart attack/stroke

Yes

No

History of cancer

Yes

No

History of liver disease

Yes

No

History of gallstones/cholecystectomy

Yes

No

History of renal disease

Yes

No
$N(\%)$

$131(12.8)$

$246(24.0)$

$64(6.3)$

$497(48.5)$

277 (27.1)

747 (72.9)

390 (38.1)

$634(61.9)$

339 (33.1)

685 (66.9)

309 (30.2)

$715(69.8)$

$210(21.5)$

814 (79.5)

386 (37.7)

126 (12.3)

$512(50.0)$

121 (11.8)

903 (88.2)

38 (3.7)

986 (96.3)

92 (9.0)

932 (91.0)

454 (44.3)

570 (55.7)

62 (6.1)

962 (93.9)

\section{Physical QOL score}

Mean \pm s.d. $\quad P$-value

$43.0 \pm 11.1$

$40.6 \pm 11.2$

$37.2 \pm 10.7$

$31.9 \pm 9.9$

$30.6 \pm 8.6$

$39.0 \pm 11.8$

$36.1 \pm 12.0$

$37.2 \pm 11.5$

$35.3 \pm 11.9$

$37.5 \pm 11.5$

$36.0 \pm 11.6$

$37.1 \pm 11.7$

$35.8 \pm 11.5$

$37.0 \pm 11.7$

$36.2 \pm 11.0$

$36.9 \pm 12.3$

$37.1 \pm 12.0$

$32.9 \pm 11.2$

$37.3 \pm 11.6$

$32.7 \pm 10.3$

$36.9 \pm 11.7$

$33.3 \pm 10.7$

$37.1 \pm 11.7$

$35.4 \pm 11.1$

$37.8 \pm 12.0$

$33.3 \pm 10.7$

$37.0 \pm 11.7$
$<0.001$

$42.4 \pm 13.2$

$42.4 \pm 12.1$

0.03

$41.5 \pm 13.4$

$42.5 \pm 12.2$

Mental QOL score

Mean \pm s.d. $\quad P$-value

$46.1 \pm 11.1$

$47.0 \pm 10.8$

$39.3 \pm 10.7$

$38.5 \pm 11.9$

$37.1 \pm 12.1$

$<0.001$

$44.4 \pm 11.7$

$41.5 \pm 12.3$

0.05

$43.0 \pm 12.2$

$41.9 \pm 12.1$

0.2

$42.7 \pm 12.3$

$41.4 \pm 12.4$

0.06

$42.9 \pm 12.1$

$41.6 \pm 11.8$

0.19

$42.7 \pm 12.3$

$41.9 \pm 11.9$

0.31

$43.9 \pm 11.7$

$42.5 \pm 12.6$

$42.5 \pm 12$.

0.002

$39.6 \pm 12.0$

0.03

$42.7 \pm 12.2$

0.002

$42.3 \pm 11.8$

0.6

$42.6 \pm 12.5$

0.02

$41.8 \pm 11.5$

0.6

$42.5 \pm 12.3$

CP, chronic pancreatitis; NAPS2, North American Pancreatitis Study 2; QOL, quality of life.

Numbers are provided in parenthesis for variables where the number of patients was less than the total sample size.

Body mass index categories: Normal/low $-\leq 25 \mathrm{~kg} / \mathrm{m}^{2}$; Overweight $\longrightarrow 25-\leq 30 \mathrm{~kg} / \mathrm{m}^{2}$; Obese $\longrightarrow 30 \mathrm{~kg} / \mathrm{m}^{2}$.

Drinking category definition: Abstainers: no alcohol use or $<20$ drinks in a lifetime; Light drinkers: 3 drinks/week; Moderate drinkers: 4-7 drinks/week for females,

4-14 drinks/week for males; Heavy drinkers: 8-34 drinks/week for females, 15-34 drinks/week for males; Very heavy drinkers: 235 drinks/week for both sexes. 


\begin{tabular}{|c|c|c|c|c|}
\hline Variable & $\begin{array}{l}\text { Reference } \\
\text { category }\end{array}$ & $\begin{array}{l}\text { Parameter } \\
\text { estimate }\end{array}$ & s.e. & $P$-value \\
\hline Intercept & - & 45.8 & 1.5 & $<0.001$ \\
\hline Age 50 years $^{a}$ & - & -0.04 & 0.02 & 0.1 \\
\hline Female & Male & -1.2 & 0.7 & 0.09 \\
\hline \multicolumn{5}{|l|}{ Pain } \\
\hline $\begin{array}{l}\text { Intermittent } \\
\text { mild-to-moderate } \\
\text { episodes of pain }\end{array}$ & No pain & -0.8 & 1.5 & 0.6 \\
\hline $\begin{array}{l}\text { Intermittent severe } \\
\text { episodes of pain }\end{array}$ & & -2.6 & 1.4 & 0.05 \\
\hline $\begin{array}{l}\text { Constant mild- } \\
\text { to-moderate pain }\end{array}$ & & -5.2 & 1.8 & 0.003 \\
\hline $\begin{array}{l}\text { Constant mild-to- } \\
\text { moderate pain with } \\
\text { episodes of severe } \\
\text { pain or constant } \\
\text { severe pain }\end{array}$ & & -10 & 1.3 & $<0.001$ \\
\hline $\begin{array}{l}\text { Disabled or } \\
\text { unemployed }\end{array}$ & $\begin{array}{l}\text { Not disabled or } \\
\text { unemployed }\end{array}$ & -5.1 & 0.8 & $<0.001$ \\
\hline \multicolumn{5}{|l|}{ Smoking status } \\
\hline Past & Never smoker & -1 & 0.9 & 0.3 \\
\hline Current & & -2.9 & 0.9 & 0.002 \\
\hline \multicolumn{5}{|l|}{ Drinking category } \\
\hline Light & Abstainer & 2.1 & 1.1 & 0.06 \\
\hline Moderate & & 4.3 & 1.2 & $<0.001$ \\
\hline Heavy & & 2.5 & 1.2 & 0.04 \\
\hline Very heavy & & 1.6 & 1.1 & 0.2 \\
\hline History of cancer & No cancer & -4.4 & 1.7 & 0.01 \\
\hline $\begin{array}{l}\text { History of heart } \\
\text { disease/heart } \\
\text { attack/stroke }\end{array}$ & $\begin{array}{l}\text { No heart } \\
\text { disease/heart } \\
\text { attack/stroke }\end{array}$ & -3.3 & 1 & 0.001 \\
\hline History of renal failure & No renal failure & -2.8 & 1.4 & 0.04 \\
\hline $\begin{array}{l}\text { History of gallstones/ } \\
\text { cholecystectomy }\end{array}$ & $\begin{array}{l}\text { No gallbladder } \\
\text { disease/chole- } \\
\text { cystectomy }\end{array}$ & -1.6 & 0.7 & 0.02 \\
\hline
\end{tabular}

$R^{2}-27 \%$.

For drinking category definition, refer to Methods section.

${ }^{a}$ Age variable centered at 50 years.

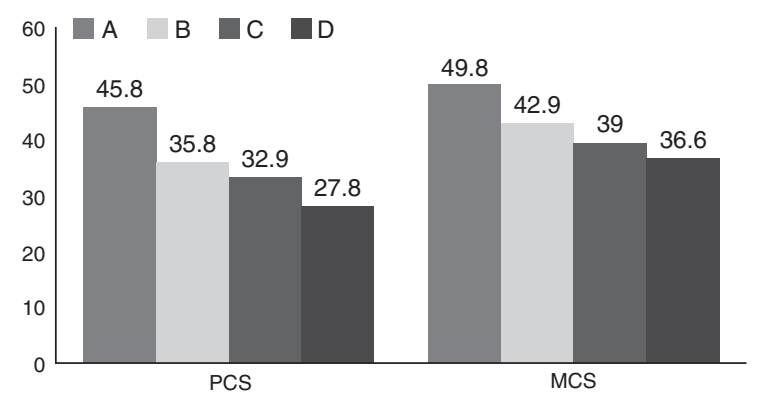

Figure 1. Each column represents a clinical scenario with additive attributes: (A) A 50-year-old man with CP who is non-smoker, has no pain, disability/unemployment, or co-morbidities. (B) Subject in A with constant mild-to-moderate pain with episodes of severe pain or constant severe pain that does not change. (C) Subject in B who is also a current smoker. (D) Subject in $\mathrm{C}$ with disability/unemployment.

of co-morbid conditions also had a significant negative impact-a history of cancer, heart disease/heart attack/stroke, and renal failure reduced the PCS score by $4.4,3.3$, and 2.8 points, respectively. Other factors associated with lower PCS scores on the univariable analysis were not significant after adjusting for other variables and were not included in the final regression model. Variables in the final multivariable model explained $27 \%$ of the variance in PCS.

To illustrate the impact of individual factors and incremental effect of predictive factors, representative PCS score for a 50-yearold man with $\mathrm{CP}$ and progressive addition of select attributes are shown in Figure 1. By adding constant mild-to-moderate pain with episodes of severe pain or constant severe pain, current smoking, and pain-related disability/unemployment, the PCS score would decrease from 45.8 to 27.8 .

\section{Predictors of mental QOL}

Univariable analysis. The mean MCS score for the study cohort was $42.4 \pm 12.2$. Univariable analysis for MCS scores based on demographics, risk factors, and clinical characteristics is shown in Table 1. A significantly lower mental QOL was noted with younger age, very heavy drinking, current smoking, disability/ unemployment, and pain. In contrast to physical QOL, mental QOL was significantly lower in patients with physician-defined alcohol etiology and the duration of disease. Race, presence of pseudocysts, and exocrine insufficiency showed borderline association with MCS score, while sex, body mass index, diabetes, other features on pancreatic morphology, and prior endotherapy or pancreatic surgery showed no association.

Multivariable analysis. The results of multivariable regression analyses for mental QOL are shown in Table 3. Similar to physical QOL, presence of pain had the most impact on mental QOL. Interestingly, compared with those patients with no pain, a negative impact was seen only for constant pain irrespective of its severity. The impact of constant mild-to-moderate pain (6.8 points) was almost similar to constant mild-to-moderate pain with episodes of severe pain or constant severe pain (6.9 points). Intermittent pain irrespective of severity did not signifi- 


\begin{tabular}{|c|c|c|c|c|}
\hline Variable & $\begin{array}{l}\text { Reference } \\
\text { category }\end{array}$ & $\begin{array}{l}\text { Parameter } \\
\text { estimate }\end{array}$ & s.e. & $P$-value \\
\hline Intercept & - & 49.81 & 1.4 & $<0.001$ \\
\hline Age 50 years $^{a}$ & - & 0.04 & 0.03 & 0.16 \\
\hline Female & Male & -0.3 & 0.8 & 0.7 \\
\hline \multicolumn{5}{|l|}{ Pain } \\
\hline $\begin{array}{l}\text { Intermittent mild-to- } \\
\text { moderate episodes } \\
\text { of pain }\end{array}$ & No pain & -1.3 & 1.6 & 0.41 \\
\hline $\begin{array}{l}\text { Intermittent severe } \\
\text { episodes of pain }\end{array}$ & & -0.2 & 1.4 & 0.87 \\
\hline $\begin{array}{l}\text { Constant mild-to- } \\
\text { moderate pain }\end{array}$ & & -6.8 & 1.9 & $<0.001$ \\
\hline $\begin{array}{l}\text { Constant mild-to- } \\
\text { moderate pain with } \\
\text { episodes of severe } \\
\text { pain or constant } \\
\text { severe pain }\end{array}$ & & -6.9 & 1.4 & $<0.001$ \\
\hline $\begin{array}{l}\text { Disabled or } \\
\text { unemployed }\end{array}$ & $\begin{array}{l}\text { Not disabled or } \\
\text { unemployed }\end{array}$ & -2.4 & 1.1 & 0.03 \\
\hline \multicolumn{5}{|l|}{ Smoking status } \\
\hline Past & Never smoker & -0.3 & 1 & 0.79 \\
\hline Current & & -3.9 & 0.9 & $<0.001$ \\
\hline Liver disease & $\begin{array}{l}\text { No liver } \\
\text { disease }\end{array}$ & -2.4 & 1.2 & 0.052 \\
\hline $\begin{array}{l}\text { Femalexdisability/ } \\
\text { unemployment }{ }^{\mathrm{b}}\end{array}$ & - & -3.7 & 1.6 & 0.02 \\
\hline $\begin{array}{l}R^{2}=17.9 \% \text {. } \\
\text { age variable centered at } \\
\text { 'A significant interaction } \\
\text { ment. }\end{array}$ & $\begin{array}{l}\text { years. } \\
\text { s found for fema }\end{array}$ & ende & bilit & mploy- \\
\hline
\end{tabular}

cantly impact MCS score compared with those patients with no pain. Current smoking (3.9 points) and pain-related disability/ unemployment (2.4 points) also significantly reduced the MCS score. An interaction was noted between gender and disability/ unemployment-the effect of disability/unemployment on MCS was an additional 3.7 points lower for women than for men. Other factors associated with lower MCS scores on the univariable analysis were not significant after adjusting for other variables and were not included in the final regression model. Variables in the final multivariable models explained $17.9 \%$ of the variance in MCS score.

To illustrate the impact of individual factors and incremental effect of predictive factors, representative MCS score for a 50-yearold CP man are shown in Figure 1. Progressive addition of select attributes, such as constant mild-to-moderate pain with episodes of severe pain or constant severe pain, current smoking, and disability/unemployment, would decrease the MCS score from 49.8 to 36.6 .
Sensitivity analysis. Sensitivity analysis after excluding patients from the original NAPS2 study showed slight differences in the estimated effect sizes but were overall consistent with the main analyses (data not shown).

\section{DISCUSSION}

In this largest prospective study to date, we found that painespecially constant, pain-related disability/unemployment, current smoking, and concurrent co-morbidities, to have a significant negative impact on the QOL of CP patients. Interestingly, physician-defined alcohol etiology, disease duration, pancreatic morphology, and prior endoscopic or surgical treatments did not independently affect QOL. These data underscore the need to better understand factors driving pain and to develop effective strategies to address them. Facilitating behavioral modification will also have an impact on QOL in these patients. As only a fraction of variance in PCS and MCS scores was explained by our analyses, future studies should focus on identifying other factors affecting the QOL of CP patients.

Pain occurs in up to $90 \%$ of CP patients, and about half of them have constant pain (9). Although the association of pain with poor QOL is consistent across studies (3,5-10), whether the effect is greater with severity or temporal nature of pain is debatable. A small single-center Polish study of 69 patients revealed that pain intensity correlates with QOL scores more often than frequency (8). More recently, Olesen et al. (10) assessed the association between the intensity and temporal pattern of pain with the QOL of 106 CP patients from two tertiary medical centers in the Netherlands and Denmark. In addition to measuring pain severity by the modified brief pain inventory short form (21), the authors used this scale to indirectly classify pain frequency into three patterns: intermittent, constant, and constant with acute exacerbations. After adjustment for confounders, they found that pain severity but not pain pattern was significantly correlated with global health status, all functional subscales, and most symptom subscales.

In $414 \mathrm{CP}$ patients enrolled in the original NAPS2 study, we reported that constant pain was associated with lower physical and mental QOL scores when compared with those who had intermittent pain (9). The present study extends those findings using multivariable analyses in a larger cohort and provides a numeric estimate of the effect of each pain type on QOL. We found that, compared with those patients with no pain, constant mild-tomoderate pain with episodes of severe pain or constant severe pain to be the strongest predictor of poor physical (10 points reduction) and mental QOL (6.9 points reduction), followed by constant mild-to-moderate pain (5.2 and 6.8 points reduction, respectively). The effect of constant pain on QOL was statistically significant, clinically relevant, and independent of other covariates such as demographics, risk factors, and co-morbidities. Intermittent severe pain had no effect on the mental QOL but had a borderline significant effect on physical QOL. These data suggest that both temporal nature and severity of pain are important to consider when designing pain management strategies and clinical 
trials in CP patients. The relevance of constant nature of symptoms was aptly demonstrated in the classic study of the natural history of alcoholic CP by Ammann et al., (22) where the temporal nature of pain was the primary determinant for the need for surgical intervention. Interestingly, constant pain has also been shown to have a significant impact on QOL in many other health conditions (23-25).

The effect of smoking on QOL in CP differs between studies. In two Italian studies, current smoking (3) and the amount and duration of smoking did not affect QOL (7). In contrast, we previously had shown and this study confirmed that current smoking had a significant impact on both physical and mental QOL (4). Similarly, Han et al. (26) reported smokers to have a significantly worse physical QOL when compared with nonsmokers. A Polish study found the duration of smoking to be associated with lower physical functioning and insomnia and the amount of smoking with worse fear of future health (8). The mechanism by which smoking has an effect on QOL is unclear. One possible explanation may be the effect of smoking on disease-related manifestations such as worsening of morphology (e.g., calcifications, exocrine and/or endocrine function) - however, it is interesting to note that morphological or functional derangements by themselves did not impact QOL. Other possible explanations would be indirect, similar to the effect of current smoking on general QOL in conditions related or unrelated to smoking (27-31). Prevalence of affective spectrum disorders in CP patients is high and patients may smoke to relieve anxiety, depression, or stress that is preexisting or develops after diagnosis of $\mathrm{CP}$ or to cope with the need to abstain from drinking (32-35). Smoking cessation by counseling and/or pharmacological measures should be an important component of the management of $\mathrm{CP}$, not only owing to its association with QOL but also for its impact on disease progression $(36,37)$. Although smoking cessation strategies show good results in many conditions, its results in $\mathrm{CP}$ can be challenging and fail in the majority of patients (26).

The independent effect of disability/unemployment on QOL has not been adequately studied. We found disability/unemployment related to $\mathrm{CP}$ to have a significant negative impact on physical as well as mental QOL. Wehler et al. (5) reported an independent reduction of PCS score caused by CP-related unemployment or early retirement. Disability/unemployment can lead to heavy psychological burden, financial distress, and disruption in social and family relationships, which can limit the ability to cope with the disease $(38,39)$. Future strategies should focus to prevent work disability and to help disabled patients to get back into the labor force (40).

Strengths of our study include a large, well-phenotyped cohort of patients and a comprehensive analysis of multiple relevant variables. This approach overcomes important limitations of prior work in this area. Our study also has limitations. First, this was a one-time assessment of QOL in patients with a chronic condition. Therefore, we are unable to evaluate for temporal changes in QOL, as well as the direct impact of interventions, such as pancreatic endotherapy or surgery, pain management, medical management of exocrine insufficiency or diabetes, etc. on QOL. We did not find a significant difference in QOL based on whether a patient had prior pancreatic endotherapy or surgery. This observation merely represents a cross-sectional assessment and does not address the question of whether performance of endotherapy or surgery improves QOL. Such a question can best be answered by studies specifically designed to evaluate changes in QOL before and after an intervention-in fact, several such studies have concluded the benefit of these interventions on QOL (11-14). A previous study of $83 \mathrm{CP}$ patients (87\% alcoholic) found the QOL to be stable over a 2-year period (41) - however, larger studies in patients with diverse etiologies with a longer follow-up period are needed to better assess temporal trends and determinants of QOL. Second, we excluded 126 patients in the original NAPS2 study who did not identify a pain pattern, and given the large sample size in the final cohort, we feel the impact of excluding these patients is likely small and would not affect the conclusions. Third, recruitment of patients mainly from referral centers and under-representation of racial groups (e.g., Hispanics, Asians, etc.) despite the multicenter effort may limit the generalizability of our findings.

Finally, even after an exhaustive evaluation of multiple factors, we only explain $27 \%$ variance in physical and $17.9 \%$ variance in mental QOL, leaving several unmeasured variables. Future studies should assess the role of factors not included in our analyses, examples of which include bowel habits (e.g., diarrhea, steatorrhea, opioid-induced constipation), malnutrition (e.g., weight loss, micronutrient deficiencies, metabolic bone disease), psychological factors (e.g., depression, anxiety, stress, sleep disturbance, substance abuse), social factors (e.g., work absenteeism, financial status, social support), health-care utilization (e.g., frequency and duration of hospitalizations), adherence to medical care, and genetics. The impact of behavioral (e.g., smoking or alcohol cessation strategies, relaxation techniques), medical (e.g., narcotics, neuromodulating agents, antidepressants, pancreatic enzyme replacement, micronutrient supplementation), endoscopic (e.g., pancreatic or biliary stenting, endoscopic shock wave lithotripsy, celiac plexus block) and surgical (e.g., drainage and resection techniques, total pancreatectomy and islet auto transplantation) interventions, and physical therapy needs further assessment. Management of CP by an interdisciplinary team with expertise in primary care, behavioral health, gastroenterology, therapeutic endoscopy, pancreatic surgery, endocrinology, and radiology has been recommended. The impact of such an approach on QOL should be empirically evaluated.

In summary, this large multicenter study demonstrated that constant pain, pain-related disability/unemployment, current smoking, and concurrent co-morbidities significantly impair the QOL of CP. These data expand our understanding that both temporal nature and severity of pain are important to consider when designing clinical trials in CP. Developing treatment strategies aimed to target modifiable factors may help in improving the QOL of $\mathrm{CP}$ patients. Future research is needed to identify factors that were not included in this study. 


\section{CONFLICT OF INTEREST}

Guarantor of the article: Dhiraj Yadav, MD, MPH.

Specific author contributions: Study design: Jorge D. Machicado, Judah N. Abberbock, and Dhiraj Yadav. Data acquisition: C. Mel Wilcox, Bimaljit S. Sandhu, Vikesh K. Singh, Andres Gelrud, Stuart Sherman, Gregory A. Cote, Samer Al-Kaade, Michelle A. Anderson, Timothy B. Gardner, Michele D. Lewis, Christopher E. Forsmark, Nalini M. Guda, Joseph Romagnuolo, John Baillie, Stephen T. Amann, Thiruvengadam Muniraj, Darwin L. Conwell, Peter A. Banks, Randall E. Brand, Adam Slivka, and Dhiraj Yadav. Statistical analysis: Judah N. Abberbock and Gong Tang. Drafting of the manuscript: Jorge D. Machicado and Dhiraj Yadav. Data interpretation, review of manuscript for important intellectual content, final approval of the manuscript: all authors.

Financial support: The study was supported by R01DK061451 (D.C.W.), R01 DK077906 (D.Y.), UO1 DK108306 (D.C.W., D.Y.), U01 DK 108320 (C.E.F.), U01 DK 108327 (D.C.), and UL1 RR024153 and UL1TR000005 (PI-Steven E. Reis, MD).

Potential competing interests: Dr Whitcomb is an inventor of intellectual property that is licensed to Ambry Genetics, which has been evaluated in this study. He also has an ownership interest in Ambry Genetics. The other authors declare no conflict of interest.

\section{Study Highlights}

\section{WHAT IS CURRENT KNOWLEDGE}

Chronic pancreatitis has a profound effect on quality of life.

Factors that determine quality of life in chronic pancreatitis patients are not well established.

\section{WHAT IS NEW HERE}

Constant pain had the most impact on quality of life of chronic pancreatitis patients.

Other independent factors were disability/unemployment related to pain, current smoking, and co-morbid conditions.

Prior endoscopic or surgical pancreatic interventions had no impact on the quality of life.

Alcohol etiology, disease duration, and pancreatic morphology had no effect on the quality of life.

\section{REFERENCES}

1. Forsmark CE. Management of chronic pancreatitis. Gastroenterology 2013;144:1282-91, e3.

2. Wehler M, Reulbach U, Nichterlein R et al. Health-related quality of life in chronic pancreatitis: a psychometric assessment. Scand J Gastroenterol 2003;38:1083-9.

3. Pezzilli R, Morselli-Labate AM, Frulloni L et al. The quality of life in patients with chronic pancreatitis evaluated using the SF-12 questionnaire: a comparative study with the SF-36 questionnaire. Dig Liver Dis 2006; 38:109-15.

4. Amann ST, Yadav D, Barmada MM et al. Physical and mental quality of life in chronic pancreatitis: a case-control study from the North American Pancreatitis Study 2 cohort. Pancreas 2013;42:293-300.

5. Wehler M, Nichterlein R, Fischer B et al. Factors associated with health-related quality of life in chronic pancreatitis. Am J Gastroenterol 2004;99:138-46.
6. Fitzsimmons D, Kahl S, Butturini G et al. Symptoms and quality of life in chronic pancreatitis assessed by structured interview and the EORTC QLQ-C30 and QLQ-PAN26. Am J Gastroenterol 2005;100:918-26.

7. Pezzilli R, Morselli-Labate AM, Fantini L et al. Assessment of the quality of life in chronic pancreatitis using Sf-12 and EORTC Qlq-C30 questionnaires. Dig Liver Dis 2007;39:1077-86.

8. Mokrowiecka A, Pinkowski D, Malecka-Panas E et al. Clinical, emotional and social factors associated with quality of life in chronic pancreatitis. Pancreatology 2010;10:39-46.

9. Mullady DK, Yadav D, Amann ST et al. Type of pain, pain-associated complications, quality of life, disability and resource utilisation in chronic pancreatitis: a prospective cohort study. Gut 2011;60:77-84.

10. Olesen SS, Juel J, Nielsen AK et al. Pain severity reduces life quality in chronic pancreatitis: Implications for design of future outcome trials. Pancreatology 2014;14:497-502.

11. Cahen DL, Gouma DJ, Nio Y et al. Endoscopic versus surgical drainage of the pancreatic duct in chronic pancreatitis. N Engl J Med 2007;356:676-84.

12. Cahen DL, Gouma DJ, Laramee P et al. Long-term outcomes of endoscopic vs surgical drainage of the pancreatic duct in patients with chronic pancreatitis. Gastroenterology 2011;141:1690-5.

13. Strate T, Bachmann K, Busch P et al. Resection vs drainage in treatment of chronic pancreatitis: long-term results of a randomized trial. Gastroenterology 2008;134:1406-11.

14. Izbicki JR, Bloechle C, Broering DC et al. Extended drainage versus resection in surgery for chronic pancreatitis: a prospective randomized trial comparing the longitudinal pancreaticojejunostomy combined with local pancreatic head excision with the pylorus-preserving pancreatoduodenectomy. Ann Surg 1998;228:771-9.

15. Whitcomb DC, Yadav D, Adam S et al. Multicenter approach to recurrent acute and chronic pancreatitis in the United States: the North American Pancreatitis Study 2 (NAPS2). Pancreatology 2008;8:520-31.

16. Wilcox CM, Yadav D, Ye T et al. Chronic pancreatitis pain pattern and severity are independent of abdominal imaging findings. Clin Gastroenterol Hepatol 2015;13:552-60, quiz e28-e29.

17. Wilcox CM, Sandhu BS, Singh V et al. Racial differences in the clinical profile, causes and outcome of chronic pancreatitis. Am J Gastroenterol 2016;111:1488-96.

18. Ware JE, Kosinski M, Turner-Bowker DM et al. How to Score Version 2 of the SF 12 Health Survey with a Supplement Documenting Version 1. QualityMetric Incorporated (Rhode Island) and Health Assessment Lab: Boston, Massachusetts, USA, 2002.

19. Ware JE, Kosinski M, Keller SD. SF-36 Physical and Mental Summary Scales: a User's Manual The Health Institute: Boston, MA, USA, 1994.

20. Pezzilli R, Morselli Labate AM, Ceciliato R et al. Quality of life in patients with chronic pancreatitis. Dig Liver Dis 2005;37:181-9.

21. Mendoza T, Mayne T, Rublee D et al. Reliability and validity of a modified Brief Pain Inventory short form in patients with osteoarthritis. Eur J Pain 2006;10:353-61.

22. Ammann RW, Muellhaupt B. The natural history of pain in alcoholic chronic pancreatitis. Gastroenterology 1999;116:1132-40.

23. Jonsdottir T, Aspelund T, Jonsdottir $\mathrm{H}$ et al. The relationship between chronic pain pattern, interference with life and health-related quality of life in a nationwide community sample. Pain Manag Nurs 2014;15:641-51.

24. Hopwood MB, Abram SE. Factors associated with failure of trigger point injections. Clin J Pain 1994;10:227-34.

25. Miller JP, Magill ST, Acar F et al. Predictors of long-term success after microvascular decompression for trigeminal neuralgia. J Neurosurg 2009;110:620-6.

26. Han S, Kheder J, Bocelli L et al. Smoking cessation in a chronic pancreatitis population. Pancreas 2016;45:1303-8.

27. Goldenberg M, Danovitch I, IsHak WW. Quality of life and smoking. Am J Addict 2014;23:540-62.

28. Strandberg AY, Strandberg TE, Pitkala K et al. The effect of smoking in midlife on health-related quality of life in old age: a 26-year prospective study. Arch Intern Med 2008;168:1968-74.

29. Wilson D, Parsons J, Wakefield M. The health-related quality-of-life of never smokers, ex-smokers, and light, moderate, and heavy smokers. Prev Med 1999;29:139-44.

30. Sippel JM, Pedula KL, Vollmer WM et al. Associations of smoking with hospital-based care and quality of life in patients with obstructive airway disease. Chest 1999;115:691-6.

31. Russel MG, Nieman FH, Bergers JM et al. Cigarette smoking and quality of life in patients with inflammatory bowel disease. South Limburg IBD Study Group. Eur J Gastroenterol Hepatol 1996;8:1075-81. 
32. Swendsen J, Conway KP, Degenhardt L et al. Mental disorders as risk factors for substance use, abuse and dependence: results from the 10-year follow-up of the National Comorbidity Survey. Addiction 2010;105: 1117-28.

33. Balliet WE, Edwards-Hampton S, Borckardt JJ et al. Depressive symptoms, pain, and quality of life among patients with nonalcohol-related chronic pancreatitis. Pain Res Treat 2012;2012:978646.

34. Nusrat S, Yadav D, Bielefeldt K. Pain and opioid use in chronic pancreatitis. Pancreas 2012;41:264-70.

35. Palfai TP, Monti PM, Ostafin B et al. Effects of nicotine deprivation on alcohol-related information processing and drinking behavior. J Abnorm Psychol 2000;109:96-105.

36. Maisonneuve P, Lowenfels AB, Mullhaupt B et al. Cigarette smoking accelerates progression of alcoholic chronic pancreatitis. Gut 2005;54:510-4
37. Luaces-Regueira M, Iglesias-Garcia J, Lindkvist B et al. Smoking as a risk factor for complications in chronic pancreatitis. Pancreas 2014;43:275-80.

38. Milner A, LaMontagne AD, Aitken $\mathrm{Z}$ et al. Employment status and mental health among persons with and without a disability: evidence from an Australian cohort study. J Epidemiol Community Health 2014;68:1064-71.

39. Baanders AN, Heijmans MJ. The impact of chronic diseases: the partner's perspective. Fam Community Health 2007;30:305-17.

40. Clayton S, Bambra C, Gosling R et al. Assembling the evidence jigsaw: insights from a systematic review of UK studies of individual-focused return to work initiatives for disabled and long-term ill people. BMC Public Health 2011;11:170.

41. Pezzilli R, Morselli Labate AM, Fantini L et al. Quality of life and clinical indicators for chronic pancreatitis patients in a 2-year follow-up study. Pancreas 2007;34:191-6. 